\title{
Aromatherapy and Acupressure Combination May Reduce Nausea Vomiting Response (Effect of Chemotherapy) to Cervical Cancer Clients
}

\author{
Kasiati, S.Kep. Ns. M. Kep \\ Lecture In State Health Polytechnic Of Malang, Republic Of Indonesia
}

\begin{abstract}
Aromatherapy and acupressure treatmentmodels are therapy complementary as a service of complementary therapy that experienced nauseaand vomiting responseas the effect of chemotherapy on cervical cancer clients, while the average person cycles of chemotherapy were 3, 4, 6 and even 12 cycles. Effects of cervical cancer chemotherapy can cause physical and psychological problems, one of the physical impactsis nausea and vomiting that can affect the delay or even can stop the next treatment cycle by the client. The purpose of this study is to determine the effectiveness of aromatherapy, acupressure, aromatherapy and acupressure treatment models on the decrease of nausea and vomiting responseas the result of chemotherapy on cervical cancer clients. This research design is quasy Experiment with Post Test - Only Non-Equivalent Control Group Design. Samples are 36 respondents. Analysis of the nausea and vomiting response variable test was done by using Mann-Whitney Test, and the data obtained as follows 1) Aromatherapy model with $p$ value 0.442, and acupressure with $p$ value $0.189(\geq 0.005)$, meaning that there is no influence of nausea and vomiting response on the cervical cancer chemotherapy client after being given the aromatherapy and acupressure treatments model, but clinically showed more normal results and minimum categories of nausea and vomiting response. 2) Aromatherapy acupressure model with $p$ value $=0.003(\leq 0: 05)$, meaning that there is a response effect of vomiting in aromatherapy acupressure treatments model group. Clients with cancer chemotherapy can use aromatherapy acupressure treatment models as non-pharmacological therapy as a complementary therapy because it may reduce nausea and vomiting response as the effects of chemotherapy, the treatment model has no side effects, is safe and easy.
\end{abstract}

Keywords:aromatherapy, acupressure, chemotherapy, nausea, vomiting

\section{Introduction}

Cervical cancer is a malignant tumor that grows in the cervix and damaging the surrounding normal tissue. Various therapeutic options can be done to treat cancer, one of the most frequently used treatments for cervical cancer is chemotherapy. Effects of cervical cancer chemotherapy can cause physical and psychological problems as nausea, vomiting, fatigue, pain, sleep disorders, and anxiety. Chemotherapy drugs such as cisplatin group, carmustine and cyclophosphamide are the type of drug that have high ability to cause side effects on client, especially nausea and vomiting over $90 \%$, although it has been given antiemetic therapy, (Hesketh, 2008)

The number of occurrence and mortality due to cervical cancer ranks second after breast cancer in the world and is responsible for more than 250,000 deaths in 2005 , and less than $80 \%$ of these deaths occur in developing countries. 2010 Health Profile states that the indicators of cervical cancer is $19.70 \%$ per 10,000 population. Until now, cervical cancer is still a women's health issue in Indonesia, and was ranked first and is one of the diseases that cause extensive psychosocial impact, especially for patients and their families (Rasjidi, 2010). Based on researcher's personal experience in taking care of two parents with cancer chemotherapy, during and after chemotherapy the toughest complaints are nausea, vomiting, body heat, fatigue, sweating, sleep disorders and hair loss.

Chemotherapy can cause any psychological and physical effects on the client. Chemotherapy drugs work systems have physical effects, one of them is the gastrointestinal tract resulting in nausea and vomiting that can lead to dehydration, electrolyte imbalances and aspiration pneumonia (Hesket, 2008). Based on Grunberg (2004) research, approximately $60 \%$ of patients receiving chemotherapy experienced nausea and $30 \%$ experienced vomiting despite using the latest antiemetic regimen. Complaints of the effects of therapy will also affect the stress, thus clients sometimes stop cycles of therapy and they also have bad potential on the healing process and reduce the quality of clients' life.

Patients with cancer can use therapy complementary which is a service of complementary therapies. Nurses' independent action to strengthen the cognator regulator and coping mechanism (Theory models Roy) in overcoming anxiety, nausea and vomiting is through complementary therapy or non-pharmacological would be better, such as the aromatherapy and acupressure model, since it is most commonly used in health care, especially by nurses (Lundie, 1994). Utilization of inhalation and massage (inhaled aromatherapy and 
acupressure) is used as a therapy because this model is the fastest, safest and the most simple, due to aromatherapy through nasal and lung mucosa have a more quickly sedative effect (Buckie, 2007). Inhaling aromatherapy can stimulate the olfactory of limbic system and the central nervous system and other aspects, the scent of lavender may cause memories and can make the clients become more relaxed. The essential oils also affect serotonin, causing a person in a state of relaxed and comfortable. Intervention and recommendation on the general use of complementary therapies such as aromatherapy and acupressure, based on some research,showsthat scent can affect cognition and behavior, the aromatherapy effect on feelings and fatigue. Research of P.H Graham etalshowsthat 313 clients who are undergoing chemotherapy inhaled therapy with essential oils of lavender that reduce anxiety and depression. Inhalation of lavender increases feelings and reduces anxiety and depression as much as 77\% of 122 patients in the ICU (Moss and Cook, 2003).

\section{General Objective}

Explain the difference between the application of aromatherapy, acupressure, aromatherapy and acupressure treatment models, and regular treatment to reduce nausea and vomiting response as the effects of chemotherapy in cervical cancer clients

\section{Specific Objectives}

1) Identify the response of nausea and vomiting in cervical cancer chemotherapy client with the application of aromatherapy treatments

2) Identify the response of nausea and vomiting in cervical cancer chemotherapy client with the application of acupressure treatment

3) Identify the response of nausea and vomiting in cervical cancer chemotherapy client with the application of a combination of aromatherapy and acupressure treatments

4) Identify the response of nausea and vomiting in cervical cancer chemotherapy client with the application of usual care according client preferences

5) Analyzing the difference in effectiveness between the implementation of aromatherapy, acupressure, aromatherapy and acupressure treatment models, and usual care according client preferences to reducevomitingresponse as the effects of cervical cancer chemotherapy

\section{Hypothesis}

There are influences of aromatherapy, acupressure, aromatherapy acupressure treatments model with usual care to reduce clients 'nausea and vomiting response as the effects of cervical cancer chemotherapy

\section{Fraework}

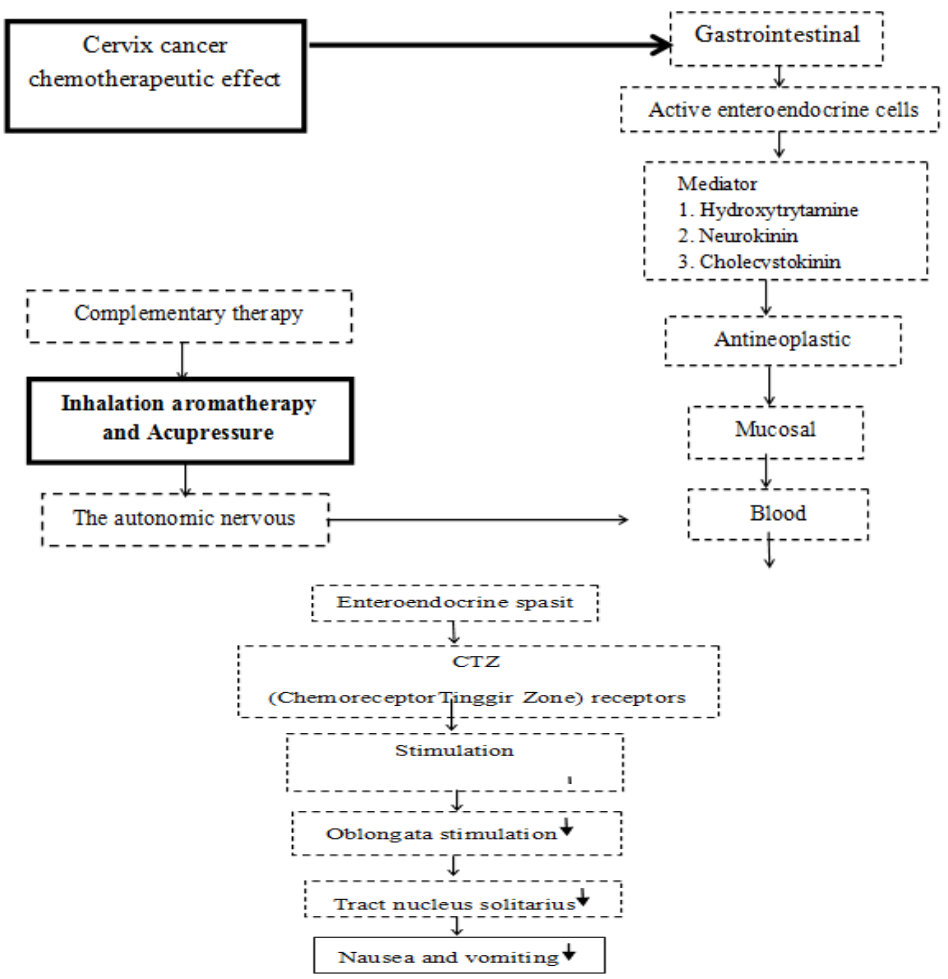




\section{Method and design}

This research method is quasy Experiment. The research design is Post Test - Only Non-Equivalent Control Group Design, in which researchers divided 4 groups: that is three (3) treatment group and one (1) control group. Before the intervention given, the four groups were observedabout the state of nausea, vomiting response. Furthermore, the intervention group performed treatment with lavender aromatherapy and acupressure, while the control group receive usual care or a non-aromatherapy. Before, during and after chemotherapy both treatment and control groups are always observed.

\section{Research Variables}

1) Independent Variables:

a. Aromatherapy treatment model

b. Acupressure treatment model

c. Aromatherapy and acupressure treatment models

\section{2) Dependent Variables:}

a. Time of occurrence of nausea and vomiting before, during and after chemotherapy

b. The response rate of nausea and vomiting as the effects of cervical cancer chemotherapy before, during and after cancer chemotherapy

The sample in this study is the client who underwent chemotherapy due to cervical cancer

\section{The inclusion criteria are as follows:}

1)Age over 25 years, 2) conscious clients, 3) cooperative, 4) undergo chemotherapy, 3) are not allergic to the essential oils, 4) like the smell of lavender, 5) like massages, 6) experience nausea and vomiting.

\section{Result and discussion}

Classification of time of occurrence of nausea and vomiting response after the application of aromatherapy, acupressure, aromatherapy acupressure treatment models and usual care on cervical cancer chemotherapy clients

Table 3.1 The Frequency distribution of intervention and control groups respondents based on the time of occurrence of nausea and vomiting as the effects of chemotherapy

\begin{tabular}{|c|c|c|c|c|c|c|c|c|}
\hline Variable & \multicolumn{2}{|c|}{ Aromatherapy } & \multicolumn{2}{|c|}{ Acupressure } & \multicolumn{2}{|c|}{$\begin{array}{l}\text { Aromatherapy } \\
\text { acupressure }\end{array}$} & \multicolumn{2}{|c|}{ Control } \\
\hline $\begin{array}{l}\text { Classification of time of occurrence of } \\
\text { nausea and vomiting }\end{array}$ & $\mathrm{F}$ & $\%$ & $\mathrm{~F}$ & $\%$ & $\mathrm{~F}$ & $\%$ & $\mathrm{~F}$ & $\%$ \\
\hline 1. Not happening & 3 & 33.4 & 4 & 44.4 & 4 & 44.4 & 1 & 11.1 \\
\hline $\begin{array}{l}\text { 2. Anticipatory } \\
(<1 \text { hour before chemotherapy })\end{array}$ & 2 & 22.2 & 2 & 22.2 & 4 & 44.4 & 2 & 22.2 \\
\hline $\begin{array}{llll}\text { 3. } & \begin{array}{l}\text { Acute }(1-\quad 24 \\
\text { chemotherapy })\end{array} & \text { hours after } \\
\end{array}$ & 4 & 44.4 & 3 & 33.4 & 1 & 11.2 & 5 & 55.6 \\
\hline $\begin{array}{l}\text { 4. Slow( }>24 \text { hours after } \\
\text { chemotherapy) }\end{array}$ & 0 & 0 & 0 & 0 & 0 & 0 & 1 & 11.1 \\
\hline Total & 9 & 100 & 9 & 100 & 9 & 100 & 9 & 100 \\
\hline
\end{tabular}

Table 3.1,based on the time of occurrence of nausea and vomiting in cervical cancer chemotherapy, shows that in the aromatherapy group model there is no nausea and vomiting in 3 respondents $(33.4 \%)$, anticipatory 2 respondents $(22.2 \%)$ and acute 4 respondents (44.4\%).

In the acupressure and acupressure and aromatherapy group models there is no nausea and vomiting in 4 mothers (44.4\%), acupressure group anticipatory 2 respondents $(22.2 \%)$ and acute 3 respondents $(33.4 \%)$, the aromatherapy acupressure model anticipatory 4 respondents $(44.4 \%)$ acute 1 respondent $(11.1 \%)$

In the control group only a small portion that is one of the respondents $(11.1 \%)$ who did not experience nausea and vomiting and in the acute group there aremore than five respondents (55.6\%).

Nausea and vomiting anticipatory occurred before chemotherapy begins. Not everyone reacts to the effects of cervical cancer chemotherapy in the same way, and certain factors can make the clients more susceptible to the treatment of nausea and vomiting. According to Garrel et al., 2003 anticipatory nausea usually occurs prior to the administration of chemotherapy in patients who have failed in controlling vomiting in the previous chemotherapy. This theory is in line with the findings that all mothers $(100 \%)$ in both groups, models of intervention and control groups, have experienced nausea in a previous chemotherapy and almost all mothers have experienced nausea and vomiting. Patients, who have shown nausea and vomiting during prechemotherapy, potentially have severe nausea and vomiting after undergoing chemotherapy.

The results also showed classification of time of occurrence of nausea and vomiting in acute classification (1-24 hours) in aromatherapy model group are 4 respondents, acupressure 3 respondents and 
control group5 respondents $(22.2 \%)$, nausea and vomiting response is classified as anticipatory, while there is 1 respondent in the aromatherapy acupressure treatment model group that occur 1-24 hours after chemotherapy. Factors that need to be noticed in the determination of chemotherapy-induced nausea and vomiting is a condition of nausea and vomiting experienced by respondents. According to Garret et al (2003) acute nausea and vomiting took place in the first 24 hours after chemotherapy. Patients who receive chemotherapy of moderate emetic risk is recommended to get antiemetic combination. Moderate emetogenic chemotherapy levels given and high with emetogenic level.

The response rate of nausea and vomiting after aromatherapy, acupressure, aromatherapy acupressure treatment models and usual care on the chemotherapy client

Table 3.2The Frequency distribution of intervention and control groups respondents based on the data of response rate of nausea and vomiting as the effects of chemotherapy

\begin{tabular}{|c|c|c|c|c|c|c|c|c|}
\hline Variables & \multicolumn{2}{|c|}{ Aromatherapy } & \multicolumn{2}{|c|}{ Acupressure } & \multicolumn{2}{|c|}{$\begin{array}{l}\text { Aromatherapy } \\
\text { acupressure }\end{array}$} & \multicolumn{2}{|c|}{ Control } \\
\hline $\begin{array}{c}\text { Category } \\
\text { Nausea and vomiting } \\
\text { response }\end{array}$ & $\mathrm{F}$ & $\%$ & $\mathrm{~F}$ & $\%$ & $\mathrm{~F}$ & $\%$ & $\mathrm{~F}$ & $\%$ \\
\hline 1. Normal & 3 & 33.3 & 4 & 44.4 & 4 & 44.4 & 1 & 11.1 \\
\hline 2. Light & 2 & 22.2 & 2 & 22.2 & 4 & 44.4 & 3 & 33.3 \\
\hline 3. Moderate & 4 & 44.4 & 2 & 22.2 & 1 & 11.1 & 5 & 55.6 \\
\hline 4. & & & & & & & & \\
\hline 5. Severe & 0 & 0 & 0 & 0 & 0 & 0 & 0 & 0 \\
\hline Total & 9 & 100 & 9 & 100 & 9 & 100 & 9 & 100 \\
\hline
\end{tabular}

From table 3.2 we know that a response rate of nausea and vomiting after being given an aromatherapy treatment on cervical cancer chemotherapy clients with the normal category of $33.3 \%$, the mild of $22.2 \%$ and the moderate of $44.4 \%$, this shows a decrease compared to the previous clients' history of nausea and vomiting that is almost all respondents ie $88.9 \%$.

The results of this research in line with the theory that aromatherapy is one complementary therapy which is a service of complementary therapies that can reduce nausea and vomiting response as the effects of cervical cancer chemotherapy. Aromatherapy treatment model is Nurses' independent action to strengthen the kognator regulator and coping mechanism (Theory models Roy) in overcoming anxiety, nausea and vomiting is through complementary therapy or non-pharmacological would be better. According to the Regulation of the Minister of Health,Complementary and Alternative Medicine or CAM is non-conventional treatment shown to improve public health, including promotive, preventive, curative, and rehabilitative acquired through structured education with quality, safety and high effectiveness based on the biomedical science. This means that complementary medicine is a traditional medicine that has been recognized and can be used as a companion to conventional / medical therapy.

Aromatherapy or scentagent carried to the olfactory nerve and stimulate sensory cells to release serotonin receptors, whereas acupressure stimulates parts of the body, affecting the receptors stimulate the activity of vagal afferent pathways that activate the vomiting center so that solitarius tract stimulation decreased.

Inhaling aromatherapy can stimulate the olfactory of limbic system and the central nervous system and other aspects, the scent of lavender may cause memories and can make the clients become more relaxed. The essential oils also affect serotonin, causing a person in a state of relaxed and comfortable.

From table 3.2 also obtained a response rate of nausea and vomiting after being given acupressure treatment model with the normal ranges as much as $44.4 \%$, while the light category $22.2 \%$, moderate $34.4 \%$, indicating that acupressure treatment model can reduce the response of nausea and vomiting in view of the minimum age of respondents 45 years, acupressure group should have a higher risk of nausea and vomiting response, than after the respondent get acupressure administration. The results of the study according to the theory that the probability of developing nausea and vomiting in patients undergoing chemotherapy depends on a variety of factors one of which is age. Age is animportant factor in this case,ie aged less than 50 years. Female patients with younger age are group of patients who have high risk of nausea and vomiting cause of chemotherapy.

The results of the study proved to be in line with the theory that the therapeutic acupressure model is a non-pharmacological therapy and non-invasive, because this therapy does not conflict with the rhythms of nature, safe because it does not incorporate certain substances into the body, and easy because anyone can learn the science of therapy acupressure correctly. According to the theory that acupressure therapy stimulates the body and according to Chinese medicine therapy, nausea and vomiting response occurs due to blockage of vital energy in stomach due to several things. Acupressure on the P6 point is believed to improve the vital energy of the stomach so that the stomach can work normally (Dibble et at. 2007 quoted Siti R, 2013). 
Research results in table 3.2 obtained a response rate of nausea and vomiting after being given aromatherapy acupressure treatment model on cervical cancer chemotherapy client in normal and lightweight categories respectively $44.4 \%$, while the moderate category fraction is $11.1 \%$ indicating that the aromatherapy acupressure treatment modelcan reduce nausea and vomiting response considering the average age of the respondents is 45 years, aromatherapy acupressure group should have higher risk of nausea and vomiting response, the result is lower than after the administration of aromatherapy acupressure.

Utilization of inhalation and massage (inhaled aromatherapy and acupressure) is used as a therapy because this model is the fastest, safest and the most simple, due to aromatherapy through nasal and lung mucosa have a more quickly sedative effect (Buckie, 2007). The results of the study proved to be in line with the theory that the therapeutic acupressure model is a non-pharmacological therapy and non-invasive, because this therapy does not conflict with the rhythms of nature, safe because it does not incorporate certain substances into the body, and easy because anyone can learn the science of therapy acupressure correctly.

According to the Regulation of the Minister of Health, Complementary and Alternative Medicine or CAM is non-conventional treatment shown to improve public health, including promotive, preventive, curative, and rehabilitative acquired through structured education with quality, safety and high effectiveness based on the biomedical science. This means that complementary medicine is a traditional medicine that has been recognized and can be used as a companion to conventional / medical therapy.

Research results in table 3.2 obtained a response rate of nausea and vomiting after being given intervention models and usual care models or hospital standards with anti-emetic drugs on cervical cancer chemotherapy clients in normal category of $11.1 \%$ and light is $55.6 \%$ more, while a small portion is $34.4 \%$. Factors that cause nausea and vomiting response is the possibility of control group mean respondent age 49 and especially at least 35 years of age. The results of the study according to the theory that the probability of developing nausea and vomiting in patients undergoing chemotherapy depends on a variety of factors one of which is age. Age is an important factor in this case, ie aged less than 50 years. Female patients with younger age are group of patients who have high risk of nausea and vomiting cause of chemotherapy.

Nausea and vomiting is one of the effects of chemotherapy that is a risk factor that is difficult to avoid due to chemotherapy as a "hard" drug, the side effects,especially the spinal cord, stomach, intestines, liver, kidneys, and even the heart. Chemotherapy has side effects. Jon Barron, an expert in food technology from Harvard and MIT, in his article entitled, 'Chemotherapy, An Interesting Choice,' wrote that the main disadvantage of chemotherapy is that these drugs not only kill cancer cells that are dividing themselves, but all dividing cells.

Chemotherapy is a systemic therapy, which means the drug spreads throughout the body and can kill cancer cells that spread ormestatage (Rasjidi, 2007, p 3)

Although the chemotherapy clients already hadantiemetic drugs that is given to prevent and treat nausea and vomiting due to chemotherapy, it is given according to the index classification of chemotherapeutic drugs. Chemotherapy antiemetic therapy is a major preventionof nausea and vomiting on the effects of chemotherapy (Hesketh, 2008).

Differences in response rate of nausea and vomiting after the application of aromatherapy, acupressure, aromatherapy acupressure treatment models and usual care on cervical cancer chemotherapy clients

Table 3.3 Results of statistical test Mann-Whitney Test response rate of nausea and vomiting as the effects of chemotherapy between the intervention and the control group

\begin{tabular}{|c|c|c|c|c|c|c|c|}
\hline \multirow[t]{3}{*}{ Treatment Model } & \multicolumn{6}{|c|}{ Nausea and vomiting response } & \multirow{3}{*}{$P$ Value } \\
\hline & \multicolumn{2}{|c|}{ Normal } & \multicolumn{2}{|c|}{ Light } & \multicolumn{2}{|c|}{ Moderate } & \\
\hline & $\mathrm{n}$ & $\%$ & $\mathrm{n}$ & $\%$ & $\mathrm{n}$ & $\%$ & \\
\hline 1. Aromatherapy & 3 & $33.3 \%$ & 2 & $22.2 \%$ & 4 & $44.4 \%$ & 0,442 \\
\hline 2. Acupressure & 4 & $44.4 \%$ & 2 & $22.2 \%$ & 3 & $33.3 \%$ & 0,186 \\
\hline $\begin{array}{l}\text { 3. Aromatherapy and } \\
\text { acupressure }\end{array}$ & 4 & $44 \%$ & 4 & $44.4 \%$ & 1 & $11,1 \%$ & 0,039 \\
\hline 4. Control & 1 & $11.1 \%$ & 3 & $33.3 \%$ & 5 & $55.6 \%$ & \\
\hline
\end{tabular}

Based on research data intable 3.2 and 3.3, the researcher obtained level of nausea and vomiting on the aromatherapy treatmentmodel with normal category ie $33.3 \%$, while the acupressure and aromatherapy acupressure group 44.4 respectively, when compared to the control group only $11.1 \%$ with the normal category.

Whereasthe results of the research on all respondents almost all of them have a history of nausea and vomiting during previous chemotherapy.Almost all respondents in the four groups get emetogenic levels moderate level chemotherapy drug, only a small number of aromatherapy group, $11.1 \%$, and $33.3 \%$ of control group receive emetogenic levels high level chemotherapy drug.

Theory says that the effects of cervical cancer chemotherapy can cause physical and psychological problems as nausea, vomiting, fatigue, pain, sleep disorders, and anxiety. Chemotherapy drugs such as cisplatin 
group, carmustine and cyclophosphamide are the type of drug that have high ability to cause side effects on client, especially nausea and vomiting over $90 \%$, although it has been given antiemetic therapy, (Hesketh, 2008). Chemotherapy antiemetic therapy is a major prevention of nausea and vomiting on the effects of chemotherapy (Hesketh, 2008).

Based on the findings, nausea and vomiting response on moderate rate control group is $55.6 \%$ which is more than the aromatherapy acupressure treatment model group that is $11.1 \%$, acupressure model group $33.3 \%$ and the aromatherapymodel group $44.4 \%$.

This fact aligned with the theory that aromatherapy and acupressure model as therapycomplementary which is a service of complementary therapies for clients who experience nausea and vomiting as the effects of cervical cancer chemotherapy. Utilization of inhalation and massage (inhaled aromatherapy and acupressure) is used as a therapy because this model is the fastest, safest and the most simple, due to aromatherapy through nasal and lung mucosa have a more quickly sedative effect (Buckie, 2007).Research of P.H Graham et al shows that 313 clients who are undergoing chemotherapy inhaled therapy with essential oils of lavender that reduce anxiety and depression. Inhalation of lavender increases feelings and reduces anxiety and depression as much as $77 \%$ of 122 patients in the ICU (Moss and Cook, 2003).

Based on the analysis of the research data, from the four groups' form of aromatherapy, acupressure, aromatherapy acupressure treatment models to therapy according to the customs on cervical cancer chemotherapy with the Mann-Whitney Test. The researcher got the results of $p$ value $0.442(\geq 0.005)$ in the aromatherapy group, and the p value $0.186(\geq 0.05)$ in acupressure group, means there is no influence of aromatherapy treatment model, acupressure treatment model on the response rate of nausea and vomiting as the effects of chemotherapy on cervical cancer respondents. According to this result, it does not mean that aromatherapy and acupressure treatment model cannot lower the nausea and vomiting response, it is clinically proven that nausea and vomiting response in aromatherapy group is as much as $33.3 \%$ of mothers and in acupressure, $44.4 \%$ of mothers did not experience nausea and vomiting, the result is more than the control group, only $11.1 \%$, with normal category. Data results in aromatherapy acupressure group obtained $p$ value $0.039(\leq 0.05)$, it means that there was an effect of aromatherapy acupressure treatment model to the response rate of nausea and vomiting as the effects of chemotherapy on cervical cancer respondents.

Aromatherapy acupressure treatmentmodel used in the study,is a combination therapy that is highly effective in the reduction of nausea and vomiting response compared to single agent that is treatment model of aromatherapy, acupressure, and therapy according to the customs (control).

This fact aligned with the theory that aromatherapy and acupressure model as therapy complementary which is a service of complementary therapies for clients who experience nausea and vomiting as the effects of cervical cancer chemotherapy. Utilization of inhalation and massage (inhaled aromatherapy and acupressure) is used as a therapy because this model is the fastest, safest and the most simple, due to aromatherapy through nasal and lung mucosa have a more quickly sedative effect (Buckie, 2007). Research of P.H Graham et al shows that 313 clients who are undergoing chemotherapy inhaled therapy with essential oils of lavender that reduce anxiety and depression. Inhalation of lavender increases feelings and reduces anxiety and depression as much as $77 \%$ of 122 patients in the ICU (Moss and Cook, 2003).

Results of research on all groups, the nausea and vomiting response as the effects of chemotherapy is still quite high compared to theory and research results that chemotherapy drugs such as cisplatin group, carmustine and cyclophosphamide are the type of drug that have high ability to cause side effects on client, especially nausea and vomiting over 90\%, although it has been given antiemetic therapy, (Hesketh, 2008). Based on Grunberg (2004) research, approximately $60 \%$ of patients receiving chemotherapy experienced nausea and $30 \%$ experienced vomiting despite using the latest antiemetic regimen.

Risk factors that are difficult to avoid that chemotherapy has side effects, according to Jon Barron, an expert in food technology from Harvard and MIT, in his article entitled, 'Chemotherapy, An Interesting Choice.'

\section{Conclusion and recommendation}

\section{Conclusion}

a. The mean score of nausea and vomiting after the application of aromatherapy treatment model in cancer chemotherapy clients is lower because they feel more relaxed

b. The mean score of nausea and vomiting after the application of acupressure treatment model incancer chemotherapy clients is lower because they feel more comfortable

c. The mean score of nausea and vomiting after the application of aromatherapy acupressure treatment model in cancer chemotherapy clients is lower because they feel more relaxed and comfortable

d. The mean score of nausea and vomiting after the application of usual treatment model in cancer chemotherapy clients is higher than the control group

e. Aromatherapy, acupressure, aromatherapy acupressure treatment models have higher effect on decreasing nausea and vomiting response than the usual treatment model group. 


\section{Recommendation}

1. Clients are expected to believe that aromatherapy, acupressure treatments model can be used as a complementary or companion therapy because it is proved to be effective, safe and easy.

2. Health workers can try aromatherapy acupressure treatment models to clients with cancer chemotherapy, as well as provide education to clients who experience nausea and vomiting during chemotherapy therapy

3. Future researchers are expected to use this research as the basis for further research on aromatherapy acupressure treatment models for clients with cancer chemotherapy.

\section{References}

[1]. Andrijono (2005) KankerGinekology. Jakarta: DepartemenObstetriGinekologyEdisi 3, (pp 59-129) Jakarta Pustaka.

[2]. Bobak.,Lowdermilk., \& Jensen. (1995). Maternity nursing.California : By Mosby.

[3]. Chang, SoYaung ( 2008), Effects of Aroma Hand Massage on Pain, State Anxiety and Depression in Hospice Patients with terminal Cancer, http://dx.doi.org/10.4040/jkan2008

[4]. Dianinda (2009) MengenalSelukBelukKanker. Jogjakarta: Katahati

[5]. Doenges, Marilynn., (1994). Rencana Perawatan Maternal/Bayi.Jakarta : EGC

[6]. D, Fellowes, K.BarnesdanS.Wilkinson (2008),,Aromatherapidan massage for symstom relief in patients with cancer,2 Desember, Web. http//onlinelibrary.wiley.com/doi/10.1002/14651858.CD002287

[7]. Hartanto, H. (2007) ObstetriGinekologi :RefrensiRingkas. Jakarta EGC

[8]. Joshi, M (2007) Cytotoxic drugs towards safer chemotherapy practices, indian Journal of cancer vol 44, no. 1 avaible at: http//search.Proquaest.com

[9]. Katie Sodenet.all ,(2004), A randomized control trial of aromatherapy massagein a hospice setting, pmj,sagepub.com,

[10]. Kozier, B \&Erb( 2000), Fundamental of Nursing, St Louis Toronto, MasbyCampanya

[11]. Manuaba, I Gde (2002) BukuSakuIlmuKandungan : Jakarta Hipokrates

[12]. Nugroho, T. (2010) Buku Ajar Ginekologi.Jogjakarta :MuhaMedika

[13]. Prawirohardjo (2005) IlmuKandungan. Yayasan Bina PustakaSarwonoPrawiroharjo

[14]. P.H.Graham,et,all,(2003) yang berjudulInhalation Aromatherapy During Radiatherapi;Results of a Placebo-Cotrolled Double- Blind Randomized Trial, journal of Clinical Oncology,Vol.21,No.12.jco.ascopub.org

[15]. Perry \& Potter, (2005), Fundamental KeperawatanKonsep,Prosesdanpraktek, edisi 4 Volume 1, EGC : Jakarta

[16]. Cara pemnyembuhandenganaromaterapi, Artikelkesehatandankedokteran, http;//fkunhas.com/tag/aplikasi-aromaterapi

[17]. ManfaatAromaterapipadaKanker, http://id,hicom.com/aromaterapi /minyak -atsiri/kesehatan

[18]. Rasjidi (2010) Imaging GinekologiOnkologi. Jakarta: Sagungseto

[19]. Rasjidi (2007) KemoterapiKankerGinekologidalamPraktiksehari-Hari.Jakarta :Sagungseto

[20]. Rasjidi (2007) PanduanPenatalaksanaanKankerBerdasarkan Evidence based. Jakarta : EGC

[21]. Rasjidi (2007) Vaksin Human Papilloma VIRUS danEradikasiKankerMulut Rahim. Jakarta: SagungSeto

[22]. Rasjidi (2006) Deteksi Dini PencegahanKankerPadaWanita.Jakarta :SagungSeto

[23]. Ramli, dkk (2005) Deteksi Dini Kanker : FK UI

[24]. Tomey,M\&Alligood (2006). Nursing theorists and their works. 6th Ed.St.Louis:Mosby Elsevier, Inc

[25]. P.H.Graham,et,all,(2003) yang berjudulInhalation Aromatherapy During Radiatherapi;Results of a Placebo-Cotrolled Double- Blind Randomized Trial, journal of Clinical Oncology,Vol.21,No.12.jco.ascopub.org

[26]. Susie M,et all,(1999), Effectiveness of Aromatherapy Massage in the Management of anxiety and Depression in Patient With Cancer : A Multicenter Rondommized Controlled Trial,diakses 1Desember,2011, Journal Of

[27]. Clinical Oncology, Vol.25.Number 5, Februari 10.2007. Web.jic.ascopubs.org 